\title{
Associations between socio-economic status and school-day dietary intake in a sample of grade 5-8 students in Vancouver, Canada
}

\author{
Naseam Ahmadi ${ }^{1}$, Jennifer L Black ${ }^{1, *}$, Cayley E Velazquez ${ }^{1}$, Gwen E Chapman ${ }^{1}$ and \\ Gerry Veenstra ${ }^{2}$ \\ ${ }^{1}$ Faculty of Land and Food Systems, University of British Columbia, 2205 East Mall, Vancouver, British Columbia, \\ Canada V6T 1Z4: ${ }^{2}$ Department of Sociology, University of British Columbia, Vancouver, Canada
}

Submitted 24 October 2013: Final revision received 5 June 2014: Accepted 19 June 2014: First published online 7 August 2014

\begin{abstract}
Objective: To examine associations between students' socio-economic status (SES) and school-day dietary intake, and the roles of parents and peers in shaping these associations.

Design: A cross-sectional survey measured school-day intake of vegetables, whole grains, low-fat milk, packaged snack foods and sugar-sweetened beverages. Logistic regression models examined associations between SES (parental education and food insecurity status) and dietary outcomes during or en route to or from school, and examined whether peer modelling or parental norms potentially mediated the associations between SES and dietary outcomes.

Setting: Twenty-six public schools in Vancouver, Canada in 2012.

Subjects: Nine hundred and fifty students in grades 5-8.

Results: Students whose parents completed some college, compared with those completing high school or less, were significantly more likely to consume vegetables daily (unadjusted $\mathrm{OR}=1.85$; $95 \% \mathrm{CI} 1.06,3 \cdot 22$ ) and students whose parents completed college or university were significantly less likely to consume sugar-sweetened beverages daily (unadjusted OR $=0 \cdot 67 ; 95 \%$ CI 0.47, 0.94). Food secure students were also significantly less likely to consume sugar-sweetened beverages daily compared with food insecure students (unadjusted OR $=0.52$; $95 \%$ CI 0.29, 0.92). Parental norms, but not peer modelling, emerged as a potential mediator of the association between SES and vegetable intake. SES was not significantly associated with the remaining dietary outcomes.

Conclusions: Higher SES was significantly associated with two of five school-day dietary outcomes and predicted higher likelihood of daily nutritious food choices at school. The present study suggests that there is room for improvement in school-day dietary quality for students from all SES backgrounds in Vancouver.
\end{abstract}

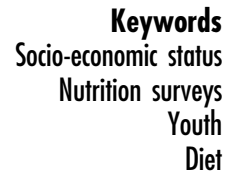

The majority of Canadian children and adolescents are not meeting national dietary recommendations for daily servings of fruit, vegetables, dairy and whole grains ${ }^{(1)}$. Low intake of these foods contributes to reduced dietary quality and is associated with increased risk of chronic health conditions such as type 2 diabetes, CVD and osteoporosis $^{(2)}$. Excessive intake of minimally nutritious, energy-dense foods and sugar-sweetened beverages (SSB) is also a growing public health concern among youth ${ }^{(1)}$. In 2004 , approximately one-quarter of the energy consumed by 14-18-year-old Canadians included foods high in sugar, fat or salt, such as candy, chocolate bars and potato chips $^{(1)}$. Moreover, the predominant items in this group were SSB such as soda pop and sweetened fruit drinks ${ }^{(1)}$.
Adolescence is a pivotal stage for developing healthy dietary habits and evidence indicates that dietary quality decreases as adolescents transition into early adulthood ${ }^{(2)}$. While little is known about Canadian students' dietary intake at school, school-aged children in the USA consume approximately $35 \%$ of their daily energy intake at school ${ }^{(3)}$, where food choices and preferences are influenced by peers and the school food environment. Mounting evidence indicates that school-based interventions can contribute to reducing diet-related chronic diseases ${ }^{(4,5)}$. However, to improve school wellness policies and programmes, questions remain about whether and how to identify high-needs students, particularly when resources for such initiatives are limited. 
Beyond the school context, socio-economic status (SES) is a well-established determinant of health, with previous research consistently indicating that dietary quality and SES are positively associated ${ }^{(6)}$. Yet much of this research has focused narrowly on intake of fruit and vegetables, indicating a need to investigate intakes of other foods, such as whole grains, low-fat dairy, SSB and energydense, nutrient-poor snack foods ${ }^{(1,7)}$. Moreover, less is known about socio-economic barriers to healthy eating for youth ${ }^{(6,8)}$, including in Canada's urban areas such as Vancouver. Vancouver is the largest municipality in British Columbia (BC), a province which maintained the highest child poverty rate in Canada for nine consecutive years (before 2009) and which continues to surpass the national child poverty rate of $13.7 \%{ }^{(9)}$. Poverty is also a key driver of household food insecurity for children, highlighted by data showing that a family of four on income assistance in BC would require over $100 \%$ of their income for shelter and food ${ }^{(10)}$. Consequently, socio-economic inequity is an important factor to consider in evaluating determinants of nutritional health among students in BC.

Previous research suggests that a differential distribution of psychosocial factors may play a role in socio-economic differences in health outcomes ${ }^{(11,12)}$. Given that SES is a difficult factor to change through health interventions alone, there is a pressing need to identify modifiable factors that mediate associations between SES and dietary outcomes, to serve as pragmatic loci for interventions aimed at reducing socio-economic disparities in nutritional outcomes. Social and psychological factors including normative beliefs and modelling are potential targets previously found to influence health- and diet-related behaviour ${ }^{(13)}$ and conceptualized by existing health behaviour theories including Social Cognitive Theory and the Theory of Planned Behaviour ${ }^{(14,15)}$. These theories, which informed the development of the present study's approach, have been used in research and health promotion initiatives to identify salient determinants of health and factors that facilitate more effective interventions $^{(16,17)}$. Yet, little is known about the role of parents and peers in explaining socio-economic differences in dietary intake ${ }^{(11)}$ or the pertinence of these issues among youth in Vancouver.

The Theory of Planned Behaviour identifies 'attitudes', 'subjective norms' and 'perceived behavioural ability' as key drivers of health behaviours ${ }^{(15)}$. An indirect measurement of subjective norms includes 'normative beliefs', which assesses an individual's perception of the degree to which important people, such as friends or family members, think the individual should perform a given behaviour ${ }^{(15)}$. Social Cognitive Theory further explains that the behaviour, situation and person domains are reciprocally influential. The social domain includes the modelling construct, which is operationalized as the degree to which an individual observes others performing a behaviour ${ }^{(18)}$. Similar to the approach by Birnbaum et al. ${ }^{(19)}$, the Theory of Planned Behaviour will be used to supplement and operationalize constructs of Social Cognitive Theory. The psychosocial constructs at the focus of the present study are normative beliefs and modelling, which are pertinent given that youth are particularly susceptible to the social influences of family and friends ${ }^{(11)}$. Therefore, targeting nutrition interventions to impact psychosocial factors hypothesized to underlie socio-economic differences in dietary intake could inform public health strategies that improve dietary quality of low-SES populations.

The present study therefore addresses gaps in the literature by: (i) describing school-day dietary intake of a sample of grade 5-8 students in Vancouver public schools; (ii) examining the associations between SES and school-day dietary intake; and (iii) exploring whether psychosocial factors potentially mediate the associations between SES and dietary outcomes.

\section{Methods}

A cross-sectional survey was conducted between March and June 2012. The study was conducted according to the guidelines laid down in the Declaration of Helsinki and all procedures involving participants were approved by the University of British Columbia Behavioural Research Ethics Board. Consent forms were sent home to parents who had the opportunity to dissent to participation by returning signed forms.

\section{Questionnaire development}

Researchers developed an online self-report questionnaire with items adapted from tools previously validated with children and adolescents wherever possible ${ }^{(19-21)}$. When no relevant tool was available, new questions were developed to address constructs of interest to the study. To evaluate readability, clarity and content validity of survey items, the questionnaire was pilot tested with graduate students and faculty members with content expertise ( $n$ 10) and students from grades 7-12 in Vancouver ( $n$ 54). Questionnaire revisions following the pilot testing were related mainly to the length and complexity of the survey including rewording questions to meet the reading abilities of respondents.

\section{Study procedures}

The sampling approach approximated a two-stage cluster sample. At the school level, participating schools were recruited from diverse Vancouver neighbourhoods that varied in terms of neighbourhood-level SES, food environment characteristics and commercial density, and the sampling strategy aimed to reach a sample of participants reflective of the demographic and food retail variability between Vancouver neighbourhoods. The Vancouver Board of Education has six defined geographic sectors and at least one school participated from each sector ${ }^{(22)}$, with a school-level participation rate of $74 \%$. 
Classes were recruited through invitations sent to teachers and school administrators. All students in participating classes were invited to participate unless their parent(s) dissented to participation or if a teacher requested that a student work on an alternative assignment (if teachers deemed the survey to be an ill-suited activity for students with insufficient English language proficiency or behavioural/ learning challenges). Participants accessed the online questionnaire on computers during class time and provided assent before participating. As incentive for participating, teachers received a $\$ C A N 20$ gift card to a local retailer and reduced-price admission for food-related professional development activities.

\section{Sample}

A total of 1175 students from twenty-six schools were present during data collection visits. Parental consent was not granted for 137 students, thirty-four declined to take part and forty-three were unable to participate due to a shortage of working computers. Eleven completed surveys were excluded due to inappropriate responses to open-ended questions, such as substantial use of vulgar language, given the assumption that these students were not taking the survey seriously and would likely bias the survey findings. The resulting final sample size was 950 students.

\section{Measures}

\section{Outcome variables}

Dietary intake was measured using an FFQ adapted from a tool used previously with Canadian students in grades $5-12^{(23)}$. The FFQ measured frequency of consumption of foods and beverages over the past $30 \mathrm{~d}$, on 'school days', defined as either during school hours or on the way to and/or from school. Response options were: never, 1 time/month, 2-3 times/month, 1 time/week, 2-4 times/ week, 1 time/d and $\geq 2$ times/d. The food categories were as follows: fruit (included fresh, frozen or dried fruit); vegetables (included fresh or frozen vegetables); whole grains (included any whole grains); low-fat milk or soya beverages (included $2 \%, 1 \%$ or skimmed milk, or soya beverages); fast foods (included pizza, hot dog, hamburger/cheeseburger, breaded/fried chicken or fish, French fries or other fried potatoes, taco or nachos, frozen packaged dinner); packaged snack foods (included salty packaged snacks, candy or chocolate bars, baked sweets, frozen desserts); and SSB (included fruit-flavoured drinks, regular pop or soft drinks, sugar-sweetened iced tea, sports drinks, energy drinks, slurpees, slushies, snow cones). These categories were defined to examine alignment with key dietary recommendations from Canada's Food Guide ${ }^{(24)}$ and provincial school nutrition guidelines ${ }^{(25)}$, and were developed in consultation with four registered dietitians.

Binary variables were constructed to define daily intake of each food category. Daily intake was calculated as any possible combination of the items within a food category that equalled intake at least once per school day or five times per week or more.

\section{Explanatory variables}

Student-level SES was assessed by two measures: parental educational attainment and food insecurity status. Parent education is the measure of SES most commonly used in youth nutrition research ${ }^{(6)}$, due to limitations in the ability of children to accurately report household income and parental occupation ${ }^{(26)}$. Student-reported parent education has similarly been used by previous child or adolescent nutrition studies ${ }^{(27-31)}$. Parent education was coded as 'high school or less' (reference group), 'some college' and 'college or university graduate'.

Food insecurity was measured by five income-related food insufficiency questions drawn from the Abbreviated Subset of the Core Module for measuring household food security developed by the US Department of Agriculture ${ }^{(32)}$. These questions are a subset of those used in the household food security module in the Canadian Community Health Survey ${ }^{(32,33)}$. The food insecurity questions were as follows:

1. 'Did the food that your family bought run out, and you didn't have money to get more?'

2. 'Were you not able to eat a balanced meal because your family didn't have enough money?'

3. 'Have you skipped a meal or has the size of your meals been cut because your family didn't have enough money for food?'

4. 'Did you have to eat less because your family didn't have enough money to buy food?'

5. 'Were you hungry but didn't eat because your family didn't have enough food?'

The following response options were adapted from the Canadian Community Health Survey measure: 'a lot', 'sometimes' and 'never'. Food insecurity was defined based on the US Department of Agriculture's Guide to Measuring Household Food Security ${ }^{(32)}$, coding 'never' to equal 0 and the 'sometimes' and 'a lot' categories to equal 1. Participants who answered affirmatively to either zero or one item were considered 'food secure', whereas students answering affirmatively to two to five items were considered food insecure with or without hunger' (reference group). Student-reported measures of food security have previously demonstrated high levels of internal consistency (Cronbach $\alpha=0.77$ ) and statistically significant inverse associations with other measures of SES and relevant indicators of diet quality outside the school context ${ }^{(34)}$.

Measures of peer modelling and parental norms were adapted from Pawlak and Malinauskas ${ }^{(21)}$ and served as the psychosocial constructs examined because modelling and norms constructs are consistently associated with dietary quality in previous studies with youth ${ }^{(35)}$. Students reported their level of agreement with statements regarding what they believe their parents think they should eat (parental norms) and what they think their friends eat 
(peer modelling). Table 1 lists the parental norms and peer modelling items. An example parental norms item was: 'How much do you agree with the following statements? My parent(s) or primary caregiver(s) think I should... Eat vegetables at least once a day'. A peer modelling question would ask, for example, 'Most of my close friends... Eat vegetables at least once a day'. The parental norms and peer modelling statements were followed by a 0-4 point Likert scale ranging from 'strongly disagree' to 'strongly agree'. The scale was collapsed into a binary scale as shown in Table 1. Sensitivity analyses (not shown) confirmed that the significance and direction of associations of psychosocial variables with related dietary outcomes were consistent between the 0-4 point Likert and binary scales. The binary psychosocial variables were coded as 'disagree or neutral' (reference group) $v$. 'agree'.

\section{Data analysis}

All data were analysed using the statistical software package STATA version 12. After conducting descriptive statistics, logistic regression was used to examine the associations between SES and dietary intake, before and after adjusting for the potential mediating influences of peer modelling or parental norms. Intakes of vegetables, whole grains, low-fat milk, packaged snack foods and SSB were examined in regression models because a corresponding psychosocial variable related to these foods was available in the questionnaire. A number of variables were considered as potential confounders including gender, school type (grade $5-7=$ elementary, grade $8=$ secondary), level of acculturation, physical activity and BMI. None of these variables was included in final models because bivariate analyses (not shown) showed no significant associations between both SES variables and these variables. Since this was a clustered sample, robust standard errors were calculated to account for the potential clustering of individuals in schools.

Univariate logistic regression models first evaluated whether parent education and/or food insecurity independently predicted each of the five dietary outcomes. If either of these SES-related variables was significantly associated with a given dietary variable, additional models tested whether either psychosocial variable potentially mediated the pathways between SES and dietary intake. Mediation was explored using the approach described by MacKinnon et al. by first examining the associations between the relevant SES variable and the hypothesized mediating variables (either parental norms or peer modelling variables). If a significant association was detected, the psychosocial variable was then retained to examine the associations between SES and the dependent variable after adjustment for the potential mediator ${ }^{(36)}$. If a significant association was identified between the independent variable and hypothesized mediator, and if after adjustment for the potential mediator, the coefficient relating the SES variable to the dietary outcome variable decreased in absolute value, then a potential for mediation was inferred and reported.
Missing values were handled using list-wise deletion. A notable proportion (28\%) of students were missing the parent education variable so models were run with the missing group included (not shown). The missing group was not significantly associated with any dietary outcomes and the model estimates were consistent with those using list-wise deletion, suggesting that findings were robust to issues related to missing data.

\section{Results}

Nearly half (48.6\%) of the sample comprised girls and participants ranged in age from 10 years to 15 years (mean $=$ 12.5 years). Table 1 describes the distribution of SES variables showing that the majority of students reported that their parents completed college or university (63.7\%), and $20.6 \%$ completed high school or less. Food insecurity (with or without hunger) was reported by $15 \cdot 8 \%$ of the sample.

\section{Scbool-day dietary intake}

Less than half of the students reported daily school-day intake of fruit (49.6\%), vegetables ( $42.3 \%)$, whole grains (34.7\%) and low-fat milk ( $46 \cdot 3 \%$; Table 2$)$. Daily schoolday intake of commonly consumed fast foods, minimally nutritious packaged snacks and SSB was reported by $17 \cdot 2 \%, 20 \cdot 3 \%$ and $31 \cdot 4 \%$ of the sample, respectively.

\section{Peer modelling and parental norms related to dietary intake}

Among the parental norms items, students most frequently agreed that their parents think that they should eat vegetables each day (83.3\%; Table 1). Most students also agreed that their parents think they should eat whole grains each day (74.0\%), drink low-fat milk (52.3\%) and avoid SSB (67.0\%). Students mostly disagreed that their parents think they should eat packaged snack foods (71.1\%).

Although students similarly agreed that their friends eat vegetables $(58.2 \%)$ and whole grains at least once per day $(50.5 \%)$, the proportion of students disagreeing with peer modelling items was higher compared with parental norms. For example, most students disagreed that their friends drink low-fat milk (65.2\%) and eat packaged snack foods $(55 \cdot 4 \%)$.

\section{Associations between socio-economic status and dietary intake}

Table 3 shows that parent education was significantly associated with daily vegetable intake in the unadjusted model. Students reporting parent education as some college were $85 \%$ more likely to report daily vegetable consumption than those reporting that their parents completed high school or less $(\mathrm{OR}=1 \cdot 85$; $95 \%$ CI 1.06 , 3.22). Food insecurity was not significantly associated with daily vegetable intake in unadjusted models and is therefore not shown in Table 3 . 
Table 1 Distribution of parental educational attainment, food insecurity status, parental norms and peer modelling of food choices among grade 5-8 students from twenty-six public schools in Vancouver, Canada, 2012

\begin{tabular}{|c|c|c|}
\hline Sample characteristic & Count & $\%$ \\
\hline \multicolumn{3}{|l|}{ Parent education† ( $n$ 681) } \\
\hline High school or less & 140 & $20 \cdot 6$ \\
\hline Some college & 107 & $15 \cdot 7$ \\
\hline Finished a university or college degree & 434 & 63.7 \\
\hline \multicolumn{3}{|l|}{ Food insecurity ( $n$ 831) } \\
\hline Food secure & 700 & $84 \cdot 2$ \\
\hline Food insecure with or without hunger & 131 & $15 \cdot 8$ \\
\hline \multicolumn{3}{|c|}{ Parental norms } \\
\hline \multicolumn{3}{|c|}{ Eat vegetables at least once per day $(n 888)$} \\
\hline Disagree or neutral & 148 & $16 \cdot 7$ \\
\hline Agree & 740 & 83.3 \\
\hline \multicolumn{3}{|c|}{ Eat whole grains at least once per day ( $n$ 882) } \\
\hline Disagree or neutral & 229 & $26 \cdot 0$ \\
\hline Agree & 653 & 74.0 \\
\hline \multicolumn{3}{|c|}{ Drink low-fat milk (e.g. 1 cup or small carton of $2 \%, 1 \%$ or skimmed milk) ( $n$ 865) } \\
\hline Disagree or neutral & 413 & 47.8 \\
\hline Agree & 452 & $52 \cdot 2$ \\
\hline \multicolumn{3}{|l|}{ Eat packaged snack foods ( $n$ 862) } \\
\hline Disagree or neutral & 613 & 71.1 \\
\hline Agree & 249 & 28.9 \\
\hline \multicolumn{3}{|c|}{ Avoid soft drinks and other sugar-sweetened beverages ( $n$ 875) } \\
\hline Disagree or neutral & 289 & 33.0 \\
\hline Agree & 586 & $67 \cdot 0$ \\
\hline \multicolumn{3}{|l|}{ Peer modelling } \\
\hline \multicolumn{3}{|l|}{ Eat vegetables at least once per day ( $n$ 849) } \\
\hline Disagree or neutral & 355 & 41.8 \\
\hline Agree & 494 & $58 \cdot 2$ \\
\hline \multicolumn{3}{|c|}{ Eat whole grains at least once per day ( $n 842$ ) } \\
\hline Disagree or neutral & 417 & $49 \cdot 5$ \\
\hline Agree & 425 & 50.5 \\
\hline \multicolumn{3}{|c|}{ Drink low-fat milk (e.g. 1 cup or small carton of $2 \%, 1 \%$ or skimmed milk) ( $n$ 831) } \\
\hline Disagree or neutral & 542 & $65 \cdot 2$ \\
\hline Agree & 289 & 34.8 \\
\hline \multicolumn{3}{|l|}{ Eat packaged snack foods ( $n$ 831) } \\
\hline Disagree or neutral & 460 & 55.4 \\
\hline Agree & 371 & 44.7 \\
\hline \multicolumn{3}{|c|}{ Avoid soft drinks and other sugar-sweetened beverages ( $n$ 841) } \\
\hline Disagree or neutral & 568 & 67.5 \\
\hline Agree & 273 & 32.5 \\
\hline
\end{tabular}

Total $n$ 950. Sample size varies between variables due to missing values.

†Highest education level of any parent or primary caregiver reported by each participant.

Positive parental norms and reporting that peers eat vegetables daily were both significantly associated with increased odds of daily school-day vegetable intake in univariate models. Compared with students reporting the lowest parental educational attainment, students whose parents completed some college (OR $=3 \cdot 72 ; 95 \%$ CI 2.01, 6.89) or college/university degrees ( $\mathrm{OR}=2 \cdot 64 ; 95 \% \mathrm{CI}$ $1.55,4.49)$ were significantly more likely to report positive parental norms related to vegetable intake; but parent education was not associated with peer modelling of vegetable intake. Students reporting that their parents think that they should eat vegetables at least once per day were over three-and-a-half times more likely to report daily vegetable intake on school days (OR $=3.55$; $95 \%$ CI 1.71 , 7.37). When models subsequently tested the association between parent education and vegetable intake adjusted for parental norms (model 4), the magnitude of the association between SES and vegetable intake decreased slightly and was no longer statistically significant. These findings suggest that parental norms may act as a mediator of the pathway between parental education and daily school-day vegetable intake.

Table 4 shows that compared with students whose parents completed high school or less, students whose parents completed college or university were significantly less likely to consume SSB daily (unadjusted OR $=0.67 ; 95 \%$ CI 0.47 , 0.94). Higher parental education was also significantly associated with higher odds of reporting that parents 'think I should avoid sugar-sweetened beverages', and in turn parental norms related to avoiding SSB were significant predictors of decreased odds of daily SSB intake (OR $=0.69$; $95 \%$ CI $0.49,0.97$ in univariate models). However, when models jointly predicted parental education and norms related to SSB avoidance, parent education remained a significant predictor of lower odds of daily SSB intake (with an odds ratio of similar magnitude to unadjusted models); whereas parental norms were no longer significantly associated with SSB intake after adjustment for parent education. 
Food secure students were also nearly half as likely to report daily SSB consumption compared with students reporting food insecurity (unadjusted $\mathrm{OR}=0.52 ; 95 \% \mathrm{CI}$ $0 \cdot 29,0 \cdot 92$ ). However, food security was not significantly associated with either psychosocial variable examined here and no evidence was found that parental norms or peer modelling mediated the association between food security (or parent education) and SSB intake on school days.

The dietary outcomes related to whole grain, low-fat milk and packaged snack food intakes did not significantly vary with either parental education or food insecurity

Table 2 Distribution of consumption of items from key food categories, at school or en route to or from school, among grade 5-8 students from twenty-six public schools in Vancouver, Canada, 2012

\begin{tabular}{|c|c|c|}
\hline Food category & Count & $\%$ \\
\hline \multicolumn{3}{|l|}{ Fruit ( $n$ 942) } \\
\hline$<1$ time/d & 475 & $50 \cdot 4$ \\
\hline$\geq 1$ time/d & 467 & $49 \cdot 6$ \\
\hline \multicolumn{3}{|c|}{ Ve⿳亠丷atables ( $n$ 930) } \\
\hline$<1$ time $/ \mathrm{d}$ & 537 & $57 \cdot 7$ \\
\hline$\geq 1 \mathrm{time} / \mathrm{d}$ & 393 & $42 \cdot 3$ \\
\hline \multicolumn{3}{|c|}{ Whole grains ( $n$ 938) } \\
\hline$<1$ time/d & 613 & $65 \cdot 3$ \\
\hline$\geq 1$ time $/ \mathrm{d}$ & 325 & 34.7 \\
\hline \multicolumn{3}{|c|}{ Low-fat fluid milk and alternatives ( $n$ 922) } \\
\hline$<1$ time/d & 495 & 53.7 \\
\hline$\geq 1$ time $/ \mathrm{d}$ & 427 & $46 \cdot 3$ \\
\hline \multicolumn{3}{|c|}{ Fast foods ( $n$ 942) } \\
\hline$<1$ time/d & 780 & $82 \cdot 8$ \\
\hline$\geq 1$ time/d & 162 & $17 \cdot 2$ \\
\hline \multicolumn{3}{|c|}{ Packaged snack foods ( $n$ 948) } \\
\hline$<1$ time/d & 756 & $79 \cdot 7$ \\
\hline$\geq 1$ time $/ \mathrm{d}$ & 192 & $20 \cdot 3$ \\
\hline \multicolumn{3}{|c|}{ Sugar-sweetened beverages ( $n$ 936) } \\
\hline$<1$ time/d & 642 & $68 \cdot 6$ \\
\hline$\geq 1$ time $/ \mathrm{d}$ & 293 & 31.4 \\
\hline
\end{tabular}

Total $n$ 950. Sample size varies between variables due to missing values. (not shown). However, there was evidence that positive parental norms related to whole grain intake were significantly positively associated with daily whole grain intake. Neither parental norms nor peer modelling was significantly associated with daily low-fat milk or packaged snack food intake.

\section{Discussion}

The present study contributes new insight regarding the school-day dietary intake of Vancouver public school students. The study found that many students are not routinely consuming fruit, vegetables, whole grains and lowfat milk during school or en route to or from school. Further, many students reported daily intake of foods recommended to be limited in intake including SSB, packaged snack foods with low nutritional value and fast food-style items typically high in sodium and saturated fat. Considering that schoolaged children consume over one-third of their daily energy intake at school ${ }^{(3)}$, the school day contributes meaningfully to total dietary quality of students. Therefore, these findings suggest that there is room for improvement in the schoolday dietary intake of Vancouver students, consistent with previous research on school-aged children in $\mathrm{BC}^{(37)}$ and other regions of Canada ${ }^{(38,39)}$.

The present study further revealed that school-day intakes of vegetables and SSB varied significantly with either parent education or food insecurity (or both), suggesting that low SES may contribute to disparities in dietary quality. These findings are comparable with research among grade 5 and 6 children in BC, which indicated a small but significant negative association between child-reported measures of affluence with fruit and vegetable intake ${ }^{(37)}$. However, low SES may not be a universal predictor of poorer dietary quality, as indicated by non-significant associations with

Table 3 Associations between daily vegetable intake and parent education, parental norms and peer modelling, from logistic regression analyses, among grade 5-8 students from twenty-six public schools in Vancouver, Canada, 2012

\begin{tabular}{|c|c|c|c|c|c|c|c|c|}
\hline & \multicolumn{8}{|c|}{ Daily vegetable intake } \\
\hline & \multicolumn{2}{|c|}{ Model 1} & \multicolumn{2}{|c|}{ Model 2} & \multicolumn{2}{|c|}{ Model 3} & \multicolumn{2}{|c|}{ Model 4} \\
\hline & OR & $95 \% \mathrm{Cl}$ & OR & $95 \% \mathrm{Cl}$ & OR & $95 \% \mathrm{Cl}$ & OR & $95 \% \mathrm{Cl}$ \\
\hline \multicolumn{9}{|l|}{ Parent education } \\
\hline High school or less (Ref.) & 1.00 & & & & & & 1.00 & \\
\hline Some college & $1.85^{\star}$ & $1.06,3.22$ & & & & & 1.57 & $0.86,2.87$ \\
\hline College or university & 1.30 & $0 \cdot 80,2 \cdot 11$ & & & & & $1 \cdot 13$ & $0.70,1.82$ \\
\hline \multicolumn{9}{|c|}{ Parental norms, vegetable consumption } \\
\hline Disagree or neutral (Ref.) & & & 1.00 & & & & 1.00 & \\
\hline Agree & & & $3.55^{\star \star *}$ & $1.71,7.37$ & & & $3.41^{* * *}$ & $1.64,7.08$ \\
\hline \multicolumn{9}{|c|}{ Peer modelling, vegetable consumption } \\
\hline Disagree or neutral (Ref.) & & & & & 1.00 & & & \\
\hline Agree & & & & & $1 \cdot 70^{\star \star \star}$ & $1 \cdot 26,2 \cdot 31$ & & \\
\hline$n$ & & 589 & & 99 & & 39 & & 39 \\
\hline
\end{tabular}

Ref., reference category.

Robust standard errors calculated to account for clustering by school.

${ }^{\star} P<0.05,{ }^{* \star \star} P<0.001$. 
Table 4 Associations between daily SSB intake and parent education, food insecurity and parental norms, from logistic regression analyses, among grade 5-8 students from twenty-six public schools in Vancouver, Canada, 2012

\begin{tabular}{|c|c|c|c|c|c|c|c|c|}
\hline & \multicolumn{8}{|c|}{ Daily SSB intake } \\
\hline & \multicolumn{2}{|c|}{ Model 1} & \multicolumn{2}{|c|}{ Model 2} & \multicolumn{2}{|c|}{ Model 3} & \multicolumn{2}{|c|}{ Model 4} \\
\hline & OR & $95 \% \mathrm{Cl}$ & OR & $95 \% \mathrm{Cl}$ & OR & $95 \% \mathrm{Cl}$ & OR & $95 \% \mathrm{Cl}$ \\
\hline \multicolumn{9}{|l|}{ Parent education } \\
\hline High school or less (Ref.) & 1.00 & & & & & & 1.00 & \\
\hline Some college & 0.65 & $0.38,1.11$ & & & & & 0.67 & $0.40,1.15$ \\
\hline College or university & $0.67^{*}$ & $0.47,0.94$ & & & & & $0.70^{*}$ & $0.49,0.99$ \\
\hline \multicolumn{9}{|l|}{ Food insecurity } \\
\hline Food insecure (Ref.) & & & 1.00 & & & & & \\
\hline Food secure & & & $0.52^{\star}$ & $0.29,0.92$ & & & & \\
\hline \multicolumn{9}{|l|}{ Parental norms, SSB avoidance } \\
\hline Disagree or neutral (Ref.) & & & & & 1.00 & & 1.00 & \\
\hline Agree & & & & & $0.69^{\star}$ & $0.49,0.97$ & 0.71 & $0.50,1.01$ \\
\hline$n$ & & 587 & & 587 & & 587 & & 587 \\
\hline
\end{tabular}

SSB, sugar-sweetened beverage; Ref., reference category.

Robust standard errors calculated to account for clustering by school.

${ }^{\star} P<0.05$.

whole grain, low-fat milk and packaged snack food intakes. Moreover, compared with studies in the USA, the magnitude and significance of associations between SES and dietary outcomes in the present sample appeared less consistent ${ }^{(40,41)}$. Still, previous Canadian studies (not focused specifically on school-day intake) have similarly reported that SES is significantly associated with some, but not all dietary outcomes tested, such as lower intakes of fruit, vegetables $^{(42)}$, milk ${ }^{(42,43)}$, vitamin $\mathrm{A}, \mathrm{C}$, iron and folate ${ }^{(44)}$, and higher intakes of $\mathrm{SSB}^{(33)}$. Overall, these studies suggest that efforts to reduce child poverty remain key components of a comprehensive strategy to improve population-level dietary outcomes.

It is possible that SES differences in dietary intake among youth are less pronounced in this sample compared with urban contexts in the USA because of the specific socio-economic context of Vancouver, where high education levels pervade many Vancouver neighbourhoods ${ }^{(45)}$. Statistics Canada reported that in 2006, 62.9\% of 25-64-yearold adults in Vancouver completed college or university education $^{(46)}$, which was similar to the student-reported parent education estimated in this sample (63.7\%). Research suggests that individuals living in neighbourhoods with high area-level SES may experience health advantages, even if they live in lower-income households ${ }^{(47)}$, because of greater local access to health services ${ }^{(47)}$ or the influence of social networks ${ }^{(12,48)}$. The high level of educational attainment in Vancouver is somewhat paradoxical in a region where the before-tax child poverty rate stands at an estimated $18.4 \%$ (in Metro Vancouver, defined by the Statistics Canada lowincome cut-off ${ }^{(9)}$, housed in a province with persistently high child poverty rates ${ }^{(49)}$. The coexistence of high educational attainment and pronounced child poverty makes research and practice aimed at narrowing the inequities between the marginalized minority and affluent majority particularly important.
Analyses of psychosocial variables suggested that parental norms were significantly associated with daily vegetable and whole grain intakes, and that peer modelling was significantly associated with daily vegetable intake, aligning with research suggesting that nutrition interventions targeting parental norms and peer modelling of healthy eating may positively influence dietary quality ${ }^{(35)}$. However, overall little compelling evidence suggested that overall parental norms or peer modelling greatly mediated associations between SES and dietary intake. One association to note was that adjusting for parental norms attenuated the statistical significance and slightly decreased the magnitude of the association between parent education and daily vegetable intake, from an odds ratio of 1.85 (unadjusted) to 1.57 , suggesting that parental norms may play a small role in mediating this association. Although further research is needed, these findings imply that school nutrition interventions targeting parental norms may abate socio-economic disparities in dietary practices, at least in regard to vegetable intake.

It is also worth noting that unlike the USA, there are no federally funded school meal programmes in Canada. In Vancouver schools, foods are available from a variety of sources including cafeterias, vending machines, school stores, fundraisers, special food days and/or sold by parents or community groups. In this sample, approximately $40 \%$ of students reported bringing lunch from home daily, and only eight of the twenty elementary schools in the study had subsidized meal programmes where parents of participating students can make anonymous contributions to help support the programme, but face no penalty if they opt not to pay or pay only a partial sum ${ }^{(50)}$. Secondary schools have varied (and often ad hoc) approaches for filling nutritional gaps for students at risk of going hungry at school. Unfortunately, it was not possible to adequately capture students' experiences with the multiple types of school food procurement programmes within the current 
analysis, or how programmes may (or may not) buffer vulnerable students from nutritional consequences at school. Due to anonymity of parents participating in the subsidized school meal programmes, students may not have been aware of whether or not their participation in the programme was subsidized. Also, students were unfamiliar with the terms 'School Lunch Program' and 'School Breakfast Program' asked on the survey, with many misinterpreting this to refer to other unrelated school events where students can purchase meals delivered to the schools. Therefore, the measures of subsidized school meal programmes could not be examined with regard to student SES.

The present study is subject to other limitations that merit consideration. The data were self-reported by students and were therefore subject to potential response error and missing data due to students' difficulty estimating usual dietary intake ${ }^{(51)}$ and parental educational attainment ${ }^{(26)}$. However, we conducted sensitivity analyses (not shown) that included a variable for the missing group on the parent education variable (i.e. parent education was coded as high school or less, some college, college/university or missing). Students with missing data (compared with the reference group) were not significantly different in likelihood of reporting daily dietary intake outcomes and inclusion of the variable for missing data did not substantially change the significance or point estimates of other coefficients. Further, previous studies have shown acceptable consistency between child- and parent-reported measures of father's and mother's education ${ }^{(52)}$ and alternative student reports of SES, such as household affluence ${ }^{(53,54)}$. Although we acknowledge the limitations inherent in using studentreported parent education, the selection of this variable as a primary explanatory variable was based on our review of the literature and evidence that parent education is the most frequently used measure in nutrition research to evaluate child and adolescent $\mathrm{SES}^{(6,27-31,44,55)}$, particularly in adolescent nutrition studies ${ }^{(27-31)}$. Previous research using a comparable measure of food security indicates that studentreported food insecurity status demonstrated strong internal consistency and is significantly negatively associated with other indicators of SES and measures of dietary quality ${ }^{(34)}$. Hence, the selection of self-reported SES measures improves the comparability of the present study's findings to other literature in this area, but future studies should consider further validating current findings using parentreported measures and other indicators of affluence.

The nature of the dietary intake instrument did not allow us to compare differences in usual energy consumption, nutrient intake or total dietary quality. However, the binary measures of daily $v$. less than daily intake of food categories were chosen because the study aimed to assess dietary health in terms of habitual intake of foods recommended by public health nutritionists and at the forefront of school food policy debates. For example, recent changes to school vending policies in $\mathrm{BC}$ now prohibit the sales of minimally nutritious foods, such as high-fat, sugary packaged foods and $\operatorname{SSB}^{(25)}$. It is also likely that due to social desirability bias, some students may under-report unhealthy foods or over-report intake of nutritious items, in which case these findings may underestimate the need for dietary improvement among Vancouver's youth. There are also other psychosocial variables that merit future consideration including nutrition knowledge and outcome expectancies.

Overall, the present study reinforces current evidence indicating the need for improvements in dietary intake among Canadian school-aged children. While some evidence emerged suggesting that higher-SES students were more likely to make healthy dietary choices in the school context, several measures of dietary intake were similarly poor among all SES groups. In this way, these findings deviate from common discourse about dietary choices, which presumes that lower-SES individuals make inferiorquality food choices. The suboptimal dietary intake among youth during school time, in combination with the inconsistent associations between SES and dietary outcomes, suggest that Vancouver students of all socio-economic backgrounds would benefit from school nutrition interventions aimed at moving the population towards dietary recommendations.

\section{Acknowledgements}

Acknowledgements: The authors would like to thank Teya Stephens, Stephanie Shulhan and Sarah Carten for their contributions to survey tool development and data collection; Jean-Michel Billette for input on data analysis and interpretation; as well as all teachers and students who participated in the Food Practices on School Days Study. Gratitude is extended to Alejandro Rojas, Think\&EatGreen@School project collaborators, and the Vancouver School Board for key input. Financial support: This study was funded by the Canadian Institutes of Health Research, by a grant entitled 'What Shapes Food Practices on School Days? Examining the Role of the School Food Environment' (FRN 119577) and a grant from the University of British Columbia Food, Nutrition and Health Vitamin Research Fund entitled 'Developing and Pilot Testing a Web-Based Questionnaire to assess Vitamin and Mineral Intake, Food Practices and Perceptions among Secondary School Students'. The research was conducted in collaboration with the Think\&EatGreen@School project, which was funded by the Social Sciences and Humanities Research Council of Canada (Community University Research Alliance). The Canadian Institutes of Health Research, the University of British Columbia Food Nutrition and Health Vitamin Research Fund, and the Social Sciences and Humanities Research Council of Canada had no role in the design, analysis or writing of this article. Conflict of interest: None. Authorship contributions: J.L.B. and G.E.C. designed the study. N.A., J.L.B. and G.E.C. developed study tools and protocols, and G.V. contributed to SES-related question development. Data collection and analysis were led 
by N.A. with oversight from J.L.B. and input from C.E.V. and G.E.C. N.A., J.L.B., C.E.V., G.V. and G.E.C. contributed to interpretation of findings. N.A. drafted the paper with key contributions from C.E.V. and J.L.B. All authors contributed to revising and editing the manuscript and approved the final draft. Ethics of human subject participation: The study was approved by the Behavioural Research Ethics Board of the University of British Columbia.

\section{References}

1. Garriguet D (2006) Overview of Canadians' Eating Habits: Findings from the Canadian Community Health Survey. Ottawa, ON: Statistics Canada.

2. Demory-Luce D, Morales M, Nicklas T et al. (2004) Changes in food group consumption patterns from childhood to young adulthood: The Bogalusa Heart Study. J Am Diet Assoc 104, 1684-1691.

3. Briefel R, Crepinsek M, Cabili C et al. (2009) School food environments and practices affect dietary behaviors of US public school children. J Am Diet Assoc 109, 2 Suppl., S91-S107.

4. Gonzalez-Suarez C, Worley A, Grimmer-Somers $\mathrm{K}$ et al. (2009) School-based interventions on childhood obesity: a meta-analysis. Am J Prev Med 37, 418-427.

5. De Bourdeaudhuij I, Van Cauwenberghe E, Spittaels $\mathrm{H}$ et al. (2011) School-based interventions promoting both physical activity and healthy eating in Europe: a systematic review within the HOPE project. Obes Rev 12, 205-216.

6. Hanson M \& Chen E (2007) Socioeconomic status and health behaviors in adolescence: a review of the literature. J Behav Med 30, 263-285.

7. Taylor J, Evers S \& McKenna M (2005) Determinants of healthy eating in children and youth. Can J Public Health 96, Suppl. 3, S22-S29.

8. Ricciuto L \& Tarasuk V (2007) An examination of incomerelated disparities in the nutritional quality of food selections among Canadian households from 1986-2001. Soc Sci Med 64, 186-198.

9. BC Child and Youth Advocacy Coalition (2012) BC Campaign 2000: 2012 Child Poverty Report Card. Vancouver, BC: BC Child and Youth Advocacy Coalition; available at http://www.firstcallbc.org/pdfs/EconomicEquality/ First $\% 20$ Call\%20BC\%20Child\%20Poverty\%20Report $\% 20$ Card \%202012.pdf

10. Dietitians of Canada (2011) Cost of Eating in British Columbia. BC: Dietitians of Canada BC Region; available at http://www.dietitians.ca/Downloadable-Content/Public/Costof EatingBC2011_FINAL.aspx

11. Lynch J \& Kaplan G (2000) Socioeconomic position. In Social Epidemiology, pp. 13-35 [L Berkman and I Kawachi, editors]. New York: Oxford University Press.

12. Richter M, Moor I \& van Lenthe F (2012) Explaining socioeconomic differences in adolescent self-rated health: the contribution of material, psychosocial and behavioural factors. J Epidemiol Community Health 66, 691-697.

13. Martikainen P, Bartley M \& Lahelma E (2002) Psychosocial determinants of health in social epidemiology. Int J Epidemiol 31, 1091-1093.

14. Baranowski T, Davis M, Resnicow K et al. (2000) Gimme 5 fruit, juice, and vegetables for fun and health: outcome evaluation. Health Educ Behav 27, 96-111.

15. Montano D \& Kasprzyk D (2002) The theory of reasoned action and the theory of planned behavior. In Health Behavior and Health Education, 3rd ed., pp. 67-98 [K Glanz, BK Rimer and FM Lewis, editors]. San Francisco, CA: Jossey-Bass.
16. Baranowski T, Lin LS, Wetter DW et al. (1997) Theory as mediating variables: why aren't community interventions working as desired? Ann Epidemiol 7, Suppl., S89-S95.

17. Baranowski T, Cullen KW \& Baranowski J (1999) Psychosocial correlates of dietary intake: advancing dietary intervention. Annu Rev Nutr 19, 17-40.

18. Baranowski T, Perry CL \& Parcel GS (2002) How individuals, environments, and health behavior interact: social cognitive theory. In Health Behavior and Health Education, 3rd ed., pp. 165-184 [K Glanz, BK Rimer and FM Lewis, editors]. San Francisco, CA: Jossey-Bass.

19. Birnbaum A, Lytle L, Murray D et al. (2002) Survey development for assessing correlates of young adolescents' eating. Am J Health Behav 26, 284-295.

20. Hanning RM, Royall D, Toews JE et al. (2009) Web-based food behaviour questionnaire: validation with grades six to eight students. Can J Diet Pract Res 70, 172-178.

21. Pawlak R \& Malinauskas B (2008) Predictors of intention to eat 2.5 cups of vegetables among ninth-grade students attending public high schools in eastern North Carolina. J Nutr Educ Behav 40, 392-398.

22. Vancouver School Board (2012) Vancouver School Board Sectoral Review. http://ourfuture.vsb.bc.ca/report/sectoralreview-mar30.pdf (accessed January 2013).

23. Propel Centre for Population Health Impact (2008) School Health Action Planning and Evaluation (SHAPES): Healthy Eating Student Questionnaire. Waterloo, ON: Propel Centre for Population Health Impact, University of Waterloo.

24. Health Canada (2007) Eating Well with Canada's Food Guide. Ottawa, ON: Health Canada.

25. British Columbia Ministry of Education and Ministry of Healthy Living (2010) Guidelines for Food and Beverage Sales in BC Schools. http://www.bced.gov.bc.ca/health/ 2010_food_guidelines.pdf (accessed June 2012).

26. Currie C, Elton R, Todd J et al. (1997) Indicators of socioeconomic status for adolescents: the WHO Health Behaviour in School-aged Children Survey. Health Educ Res 12, 385-397.

27. Delva J, O'Malley P \& Johnston L (2007) Availability of morehealthy and less-healthy food choices in American schools: a national study of grade, racial/ethnic, and socioeconomic differences. Am J Prev Med 33, 4 Suppl., S226-S239.

28. Lytle LA, Varnell S, Murray DM et al. (2003) Predicting adolescents' intake of fruits and vegetables. J Nutr Educ Behav 35, 170-178.

29. Roos EB, Karvonen S \& Rahkonen O (2004) Lifestyles, social background and eating patterns of 15-year-old boys and girls in Finland. J Youth Stud 7, 331-349.

30. Stang J, Kong A, Story M et al. (2007) Food and weightrelated patterns and behaviors of Hmong adolescents. J Am Diet Assoc 107, 936-941.

31. Terry-McElrath Y, O'Malley P, Delva J et al. (2009) The school food environment and student body mass index and food consumption: 2004 to 2007 national data. J Adolesc Health 45, 3 Suppl., S45-S56.

32. Bickel G, Nord M, Price C et al. (2000) Guide to Measuring Household Food Security, Revised 2000. Alexandria, VA: FNS/USDA.

33. Statistics Canada (2007) Income-Related Household Food Security in Canada. Canadian Community Health Survey, Cycle 2.2, Nutrition (2004). http://www.hc-sc.gc.ca/fn-an/surveill/nutrition/commun/supp_table_tableau-eng.php (accessed June 2012).

34. Gulliford MC, Mahabir D, Nunes C et al. (2005) Selfadministration of a food security scale by adolescents: item functioning, socio-economic position and food intakes. Public Health Nutr 8, 853-860.

35. McClain A, Chappuis C, Nguyen-Rodriguez S et al. (2009) Psychosocial correlates of eating behavior in children and adolescents: a review. Int J Behav Nutr Phys Act 6, 54. 
36. MacKinnon DP, Fairchild AJ \& Fritz MS (2007) Mediation analysis. Annu Rev Psychol 58, 593-614.

37. Attorp A, Scott JE, Yew AC et al. (2014) Associations between socioeconomic, parental and home environment factors and fruit and vegetable consumption of children in grades five and six in British Columbia, Canada. BMC Public Health 14, 150.

38. Hanning R, Woodruff S, Lambraki I et al. (2007) Nutrient intakes and food consumption patterns among Ontario students in grades six, seven, and eight. Can J Public Health 98, $12-16$.

39. Day M, Strange K, McKay H et al. (2008) Action schools! BC-Healthy Eating: effects of a whole-school model to modifying eating behaviours of elementary school children. Can J Public Health 99, 328-331.

40. Xie B, Gilliland FD, Li Y-F et al. (2003) Effects of ethnicity, family income, and education on dietary intake among adolescents. Prev Med 36, 30-40.

41. Fahlman MM, McCaughtry N, Martin J et al. (2010) Racial and socioeconomic disparities in nutrition behaviors: targeted interventions needed. J Nutr Educ Behav 42, $10-16$.

42. Kirkpatrick SI \& Tarasuk V (2008) Food insecurity is associated with nutrient inadequacies among Canadian adults and adolescents. J Nutr 138, 604-612.

43. Mark S, Lambert M, O'Loughlin J et al. (2012) Household income, food insecurity and nutrition in Canadian youth. Can J Public Health 103, 94-99.

44. Johnson-Down L, O'Loughlin J, Koski K et al. (1997) High prevalence of obesity in low income and multiethnic schoolchildren: a diet and physical activity assessment. J Nutr 127, 2310-2315.

45. Human Early Learning Partnership (2009) SES Mapping Package. School District 39: Education. http://earlylearning. ubc.ca/media/mapsets/ses_t1t2/SD_39_SES/SD39_Van_SES T1T2.pdf (accessed February 2013).
46. Statistics Canada (2006) Census of Canada, 2006. Cumulative profile and release components (table). ABACUS (database). Using Beyond 20/20 (distributor). http://hdl.handle.net/ 10573/41852 (accessed March 2013).

47. Browning CR \& Cagney KA (2003) Moving beyond poverty: neighborhood structure, social processes, and health. J Health Soc Behav 44, 552-571.

48. Galobardes B, Shaw M, Lawlor D et al. (2006) Indicators of socioeconomic position (part 1). J Epidemiol Community Health 60, 7-12.

49. BC Child and Youth Advocacy Coalition (2011) BC Campaign 2000: 2011 Child Poverty Report Card. Vancouver, BC: BC Child and Youth Advocacy Coalition; available at http://www.firstcallbc.org/pdfs/economicequality/ 3-reportcard2011.pdf

50. Vancouver School Board (2009) Vancouver Board of Education inner city schools project review report and recommendation. https://www.vsb.bc.ca/sites/default/files/ schoolfiles/Resources/ICP_Recommendations_Report_May_ 2009.pdf (accessed January 2013).

51. Gibson R (2005) Validity in dietary assessment methods. In Principles of Nutritional Assessment, 2nd ed., pp. 149-196. New York: Oxford University Press.

52. Lien N, Friestad C \& Klepp K-I (2001) Adolescents' proxy reports of parents' socioeconomic status: how valid are they? J Epidemiol Community Health 55, 731-737.

53. Aarø LE, Flisher AJ, Kaaya S et al. (2009) Parental education as an indicator of socioeconomic status: improving quality of data by requiring consistency across measurement occasions. Scand J Public Health 37, 16-27.

54. Wardle J, Robb K \& Johnson F (2002) Assessing socioeconomic status in adolescents: the validity of a home affluence scale. J Epidemiol Community Health 56, 595-599.

55. Wall M, Larson N, Forsyth A et al. (2012) Patterns of obesogenic neighborhood features and adolescent weight: a comparison of statistical approaches. Am J Prev Med 42, e65-e75. 